\title{
A Green Energy Research: Forecasting of Wind Power For A Cleaner Environment Using Robust Hybrid Metaheuristic Model
}

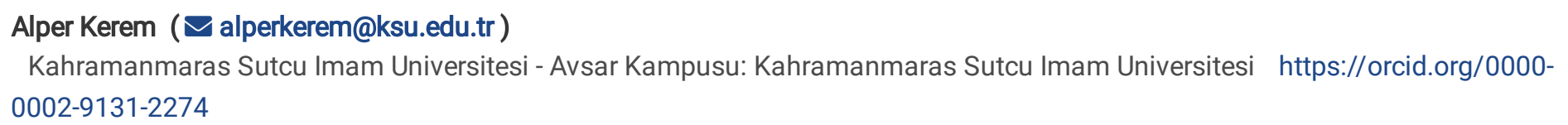

Ali Saygin

Gazi University: Gazi Universitesi

Rasoul Rahmani

Swinburne University of Technology - Hawthorn Campus: Swinburne University of Technology

\section{Research Article}

Keywords: Green energy, wind power forecasting, sustainability, hybrid metaheuristic model, artificial neural network (ANN), particle swarm optimization (PSO), radial movement optimization (RMO)

Posted Date: August 23rd, 2021

DOl: https://doi.org/10.21203/rs.3.rs-651439/v1

License: (9) (1) This work is licensed under a Creative Commons Attribution 4.0 International License. Read Full License 


\section{Abstract}

Wind is a stochastic and intermittent renewable energy source. Due to it's nature, it is extremely hard to forecasting of wind power. Accurate wind power forecasting can be encouraging and motivating for investors to shed light on future uncertainties caused by global warming. Thus, $\mathrm{CO}_{2}$ and other greenhouse gases which are harmful to the environment will not be released into the atmosphere, while generating electrical energy. This paper presents a novel precise, fast and powerful hybrid metaheuristic wind power forecasting approach based on statistical and mathematical data from real weather stations. The model was developed as a hybrid metaheuristic algorithm based on Artificial Neural Networks (ANNs), Particle Swarm Optimization (PSO) and Radial Movement Optimization (RMO). Real-time wind data was gathered from Wind Measuring Stations (WMS) at two separate places in Burdur and Osmaniye cities, Turkey. The key contribution of this new model is the ability to perform wind power forecasting studies, without needing wind speed data, with high accuracy and rapid solutions. Also, it has been carried out wind power forecasting studies with high accuracy despite the height differences between the sensors. That is, for WMS-1 and WMS-2, it has succeeded the wind power forecasting at $61 \mathrm{~m}$ and $60.3 \mathrm{~m}$ using temperature $(3 \mathrm{~m})$, humidity $(3 \mathrm{~m})$, and pressure $(3.5 \mathrm{~m})$ data. The performance results were presented in tables and graphs.

\section{Introduction}

Because of the world's increased population and developing industries, the demand for electrical energy is increasing. It is known that the fossil-based sources will be consumed in the future, therefore, sustainable and renewable types of energy resource such as wind energy has become very popular in the past decade. Wind energy has a wide range of applications that are rapidly expanding, unlimited, environmentally friendly, and cost-effective. It has a bright feature, however, due to its stochastic and intermittent nature, it is hard to predict accurately (Xiaochen et al., 2011; Yang et al., 2013; Yang \& Shaoshuai, 2016).

Wind power forecasting is highly dependent on the wind speed forecasting process. The wind power forecast is essential and significant for determining the locations of wind plants to be built in (Varanasi \& Tripathi, 2016), power system quality, grid reliability, energy planning (Rahmani et al, 2013; Lund, 2005; Debbağ \& Yilmaz, 2015), energy transformation efficiency and interconnected network operations (Riahy \& Abedi, 2008).

The wind parameters such as wind speed, wind direction, temperature, humidity, and pressure must be measured and recorded for at least 12 months to determine the power of the wind power plant to be constructed. This period may be extended due to climate changes caused by global warming (Kerem et al, 2014). The most accurate wind power forecasting studies depending on the collected data might be encouraging and motivating for investors by providing light on future concerns. Thus, the significance of accurate wind power forecasting studies is once again highlighted.

The wind is a flow of air in motion and there is the kinetic energy of an object in motion. Thus, the theoretical power obtained from the wind can be calculated with (1) (Patel, 1942; Golding, 1955);

$P_{r}=1 / 2 \rho_{a} A_{T} V_{r}^{3}(W)(1)$

where, air density $\left(\rho_{a}: 1.225 \mathrm{~kg} / \mathrm{m}^{3}\right)$, wing sweeping area $\left(A_{T}, \mathrm{~m}^{2}\right)$ and wind speed $\left(V_{n} \mathrm{~m} / \mathrm{s}\right)$. Temperature, atmospheric pressure, slope and air components are effective in air density. Thus, the air density can be calculated with (2) if the temperature $(T)$ and height $(Z)$ of the zone are known;

$\rho_{a}=(353.049 / T) \cdot e^{\left(-0.034^{\wedge} Z / T\right)}(2)$

The above equations explain the theoretical wind power. In fact, according to Betz Law, the power value to be taken from the unit wind is $59 \%$ of the wind power it carries $\left(C_{p}=0.59\right)$. The max power to be taken from the wind turbine is calculated in (3) (Ragheb \& Ragheb, 2011; Gourieres, 1982);

$P_{r}=1 / 2 \rho_{a} A_{T} V r^{3} C_{p}(W)(3)$

Figure 1 Kinetic energy flow of wind around a wind turbine (Rahmani et al., 2010)

Energy of the air passing through the wings can be defined as follows (4) (Çetin, 2006); 
$E_{k}=E_{k l n}-E_{k O u t}(N m)(4)$

Kinetic energy $\left(E_{k}\right)$ of the wind in motion is calculated in (5) and wind power $\left(P_{T}\right)$ is shown in (6);

$E_{k}=1 / 2 \rho_{a} A_{T} V_{r 1}\left(V_{r}^{2}-V_{r 2}^{2}\right)(N m)(5)$

$P_{T}=E_{k} / t=1 / 2 \rho_{a} A_{T} V_{r 1}\left(V_{r}^{2}-V_{r 2}{ }^{2}\right)(W)(6)$

In literature, Rahmani et al., (2013) developed a hybrid model of Ant Colony Optimization (ACO) and PSO for short term wind energy estimation. To observe the performance of the hybrid model they used 364 days data from Binaloud wind farm. The proposed model predicted wind power as 3.513\% using MAPE. Pousinho et al., (2010) developed a hybrid model of Particle Swarm Optimization (PSO) and Adaptive Neuro-Fuzzy Inference Systems (ANFIS) models for short-term wind power estimation. They analyzed the performance of the model and found the Mean Absolute Percent Error (MAPE) as 5.41\%. Liang et al., (2015) designed a hybrid model of Hilbert Hur Huang Transform (HHT) and Hurst Analysis (HA) for wind power estimation. Using the Empirical Mode Decomposition (EMD) + Least Square Support Vector Machine (LSSVM) + Extreme Learning Machine (ELM) hybrid models they decreased to error values from $49.45 \%$ and $44.30 \%$ to 37.96 and $27.12 \%$, respectively. Zhang et al., (2015) designed a hybrid estimation model of EMD + Support Vector Machine (SVM) for wind power estimation. They used the EMD to convert the wind energy sequence into a variety of internal functions, and the SVM used to optimize the optimal parameters and each component of the kernel function. According to analysis results, it is observed that the developed EMD + SVM hybrid model has significantly increased the wind power estimation accuracy. Kassa et al., (2016) designed a hybrid estimation model that includes ANN based Genetic Algorithm (GA) + Back Propagation (BP) models for wind power prediction. GA -optimized and BP - trained algorithm of multi-layer ANNs were used in this model. In order to test the performance of the model, they used the data of $2.5 \mathrm{MW}$ wind turbine in Beijing. Catalao et al., (2011) developed a triple hybrid prediction model of Wavelet + PSO + ANFIS models for short term wind power estimation. In order to test the performance of the proposed model, they used data from the National Electricity Network (REN) in Portugal. They were compared to the success of the new model with other models such as Persistence, NRM, ARIMA, Neural Networks (NN), NNWT, NF and Wavelet + Neuro + Fuzzy (WNF). It was observed that the new hybrid model had better MAPE and NMAE error values. Osório et al., (2015) developed a hybrid estimation model of Wavelet Transform (WT), ANFIS, Evolutionary Particle Swarm Optimization (EPSO) and Mutual Information (MI) algorithms for short term wind power estimation. They observed the performance of the WT + ANFIS + EPSO + MI hybrid model were more successful than previous prediction algorithms. Azimi et al., (2016) designed a hybrid model based on time series that includes Time-Series Based K-Means Clustering Method (TSBK) and Cluster Selection Algorithm (CSA) for wind power estimation. In this model TSBK, Discrete Wavelet Transform (DWT) and Harmonic Analysis Time Series (HANTS) and Multilayer Perceptron Neural Network (MLPNN) algorithms were used to increase the accuracy of wind energy estimation. The task of TSBK is to separate the data into separate groups, identifying abnormal and irregular patterns and providing more appropriate learning for neural networks. That improves the accuracy of the estimated results. They applied the CSA to identify the best-trained cluster for MLPNN. The data were separated by Daubechies D4 wavelet transform and filtered by HANTS. They tested the performance of the developed model on the data obtained from different wind farms in the USA. The new hybrid model showed superior success according to the results of the analysis. Liu et al., (2015) developed a hybrid Relevance Vector Machine (RVM) model for wind power estimation. There are five Kernel Functions in this model that Gaussian Kernel, Laplacian Kernel, Cauchy in Distance Kernel, R (distance) Kernel and Thin-plate spline Kernel (Tps). The SVM prediction model used one by one with each Kernel. According to the analysis they observed that the proposed hybrid RVM model was more compatible with the Kernel parameters and obtained more accurate results than the other individual kernel models. Haque et al., (2014) designed the WT + FA + FF + SVM hybrid model for wind power estimation consisting of WT, Fuzzy Artmap (FA), Firefly (FF) and SVM. They have combined WT and FA algorithms for wind power estimation and optimized with FF. They used SVM to minimize wind power estimation errors obtained from WT + FA + FF. They tested the success of the hybrid model by using the wind power data from the Cedar Creek wind farm in Colorado. Chitsaz et al., (2015) used the Wavelet Neural Network (WNN) model trained with the Enhanced Clone Selection Algorithm (CSA) for wind power estimation. They used the Maximum Correntropy Criterion (MCC) instead of MSE in the estimation process. They used real-time hourly data of the wind turbine in Alberta, Canada in order to test the performance of the model. They compared the success of the model with other techniques and observed that this new model obtained more successful results. Osório et al., (2012) developed a hybrid prediction model of the WT, EPSO and ANFIS models for short-term wind power estimation. They found that the proposed model had MAPE of $4.28 \%$ and calculation time of less than $1 \mathrm{~min}$. Thus, they have obtained much more accurate estimation and short computation time than the other techniques in the literature. Kusiak et al., (2009) designed the MLP + kNN hybrid model for wind power estimation. And, they presented two basic estimation studies. The first one is the direct prediction model where the power estimate is derived directly from

Page 3/19 
the weather forecast data. The other one is an integrated forecasting model which is produced by the estimated air data of the wind speed and then generated by the estimated wind speed and power. They examined the performance of the model for different time periods of 12 hours and 84 hours. They observed that the direct prediction model had better prediction performance than the hybrid prediction model. Catalao et al., (2011) developed a new hybrid model based on the WT model and a hybrid of NNs + Fuzzy Logic (FL) model for short term wind power estimation in Portugal. The proposed WNF hybrid model obtained MAPE value as $5.99 \%$. Sharifian et al., (2018) designed a new hybrid prediction model called T2FNN + PSO to develop Type-2 Fuzzy Neural Network (T2FNN). This new model combines both the expert knowledge of the fuzzy system and the ability of the NNs to learn for accurate estimation of wind power.

In this study, to make a highly accurate wind power prediction, a newer and powerful hybrid metaheuristic approach called ANNs+ (PSO-RMO) was used. Data was gathered from Wind Measuring Stations (WMS) located at various locations in the Burdur and Osmaniye cities for WMS-1 and WMS-2, respectively. To compare the effectiveness of ANNs+(PSO-RMO) approach, the other hybrids such as ANNs + ACO, ANNs + GA, ANNs + PSO, ANNs + RMO were designed. 50run was used to evaluate the performance of all developed hybrid metaheuristic models.

The main contributions of this study are;

1. Accurate wind power forecasting can be encouraging and motivating for investors to shed light on future uncertainties caused by global warming. Thus, $\mathrm{CO}_{2}$ and other greenhouse gases will not be released into the atmosphere as a consequence of focusing energy generation to clean, ecologically friendly, and renewable energy rather than fossil-fueled power plants.

2. The ANNs+(PSO-RMO) model is able to perform wind power forecasting studies with high accuracy, rapid and reliability without needing wind speed data, which is a vital parameter.

3. Wind power forecasting studies could be performed despite the height differences between the sensors. That is, wind power forecasting studies at $61 \mathrm{~m}$ and $60.3 \mathrm{~m}$ were performed using temperature $(3 \mathrm{~m})$, humidity $(3 \mathrm{~m})$ and pressure $(3.5 \mathrm{~m})$ data for WMS-1 and WMS-2, respectively.

4. The effectiveness of the designed hybrid metaheuristic approach has been tested on real-time data taken from two distinct coordinates and the model success has been confirmed even at abrupt fluctuations.

5. This proposed model is proved to be more effective than the GA, ACO, PSO, and RMO models commonly used in the literature.

6. With this study, the wind power forecasting studies have been applied to ANNs+(PSO-RMO) model for the first time in the literature.

\section{Data Processing In Terrain}

The WMS were placed at two separate locations. The WMS-1 was situated at UTM E263.254 and N4.173.479 coordinates with an altitude of $1313 \mathrm{~m}$ and a $63 \mathrm{~m}$ total height in Burdur. The WMS-2 was situated at E285.866 - N4.122.267 coordinates, $1028 \mathrm{~m}$ altitude and $60.3 \mathrm{~m}$ total height in Osmaniye. WMS-1 and WMS-2 data were gathered in 2014 (August) and 2009 (October), respectively.

Technical data for WMS-1 and WMS-2 are given in Table I. Installation works of WMS-1 and sensors are given in Fig. 3. 
Table 1

Technical data for WMS-1 and WMS-2

\begin{tabular}{|lllll|}
\hline WMSs & \multicolumn{2}{l}{ input variables } & output variable \\
\cline { 2 - 5 } & temperature & humidity & pressure & wind power \\
\hline WMS-1: Burdur & $4 \mathrm{~m}$ & $4 \mathrm{~m}$ & $3.5 \mathrm{~m}$ & $61 \mathrm{~m}$ \\
UTM E263.254 - N4.173.479 & & & & \\
1313m altitude & & & & \\
$\begin{array}{l}\text { WMS-2: Osmaniye } \\
\text { UTM E285.866 - N4.122.267 }\end{array}$ & $4 \mathrm{~m}$ & $4 \mathrm{~m}$ & $3.5 \mathrm{~m}$ & $60.3 \mathrm{~m}$ \\
1028m altitude & & & & \\
\hline
\end{tabular}

Table 2

Statistical values of WMS-1 data (august) and WMS-2 data (october)

\begin{tabular}{|c|c|c|c|c|c|c|c|c|c|c|}
\hline \multirow[t]{2}{*}{ Parametreler } & \multicolumn{5}{|c|}{ WMS-1 } & \multicolumn{5}{|c|}{ WMS-2 } \\
\hline & $\begin{array}{l}\text { Wind } \\
\text { speed } \\
(\mathrm{m} / \mathrm{s})\end{array}$ & $\begin{array}{l}\text { Wind } \\
\text { aspect } \\
\left({ }^{\circ}\right)\end{array}$ & $\begin{array}{l}\text { Temp. } \\
\left({ }^{\circ} \mathrm{C}\right)\end{array}$ & $\begin{array}{l}\text { Humidity } \\
\text { (\%) }\end{array}$ & $\begin{array}{l}\text { Pressure } \\
\text { (mbar) }\end{array}$ & $\begin{array}{l}\text { Wind } \\
\text { speed } \\
(\mathrm{m} / \mathrm{s})\end{array}$ & $\begin{array}{l}\text { Wind } \\
\text { aspect } \\
\text { ( })\end{array}$ & $\begin{array}{l}\text { Temp. } \\
\text { (K) }\end{array}$ & $\begin{array}{l}\text { Humidity } \\
\text { (\%) }\end{array}$ & $\begin{array}{l}\text { Pressure } \\
\text { (mbar) }\end{array}$ \\
\hline Average & 4.592 & 161.689 & 23.101 & 46.638 & 865.763 & 3.193 & 164.019 & 2837.722 & 65.631 & 900.241 \\
\hline Median & 4.435 & 156.717 & 23.396 & 47.642 & 866.348 & 2.781 & 160.697 & 2831.93 & 65.299 & 900.801 \\
\hline Std dev. & 0.991 & 56.931 & 2.356 & 13.329 & 2.354 & 1.403 & 47.309 & 24.339 & 15.413 & 4.003 \\
\hline Mod & 5.165 & 149.179 & 21.087 & 61.67 & 867.423 & 4.429 & 131.637 & 2829.647 & 92.284 & 900.552 \\
\hline Maximum & 8.797 & 282.038 & 28.409 & 76.673 & 870.448 & 7.239 & 316.6 & 2896.92 & 93.378 & 906 \\
\hline Minumum & 2.432 & 41.013 & 17.217 & 26.791 & 861.358 & 0.556 & 79.458 & 2801.254 & 37.891 & 887.388 \\
\hline Skewness & 0.939 & 0.092 & -0.259 & 0.292 & -0.136 & 1.136 & 0.145 & 0.805 & 0.169 & -1.288 \\
\hline Kurtosis & 2.604 & -0.729 & -0.436 & -1.089 & -0.64 & 0.568 & -0.741 & -0.265 & -1.186 & 1.678 \\
\hline Variance & 0.981 & 3241.174 & 5.551 & 177.654 & 5.544 & 1.968 & 2238.172 & 592.375 & 237.563 & 16.022 \\
\hline Sample item & 4464 & 4464 & 4464 & 4464 & 4464 & 4319 & 4319 & 4319 & 4319 & 4319 \\
\hline
\end{tabular}

\section{Powerful Hybrid Metaheuristic Approach}

The hybrid approach composed of two distinct metaheuristic algorithms of PSO and RMO given in Sect. 3.1 and 3.2.

Particle Swarm Optimization (PSO)

PSO is a two-dimensional model of the combined behavior of bird and fish swarms in food-search scenarios. It is a metaheuristic algorithm which, in terms of computation, is quick and effective, and simple in terms of understanding and implementation (Kennedy \& Eberhart,1995).

\section{Radial Movement Optimization (RMO)}

RMO is a metaheuristic optimization algorithm that fastly works, swarm-based, simple and effective. It was structured to optimize complex and non-linear issues spherically, using a vector's spherical limits in the quest space to find the optimum solution. The algorithm is initialized by launching the particles in the search space that demonstrates the solutions to the problem (Rahmani \& Yusof, 2014; Mahrami et al., 2016; Seyedmahmoudian et al., 2016). 
Once the center point $\left(c_{p}\right)$ has been achieved the next step is to scatter the particles from the $c_{p}$. The particles are moved through the

$V_{i j}$ vector based $c_{p}$ through the radius in straight lines. The next step is to evaluate the appropriateness of all particles after scattering. The particle containing the best fit value is taken as the best radial (Rbest). The locations of the Gbest and Rbest particles are used to update a new best $c_{p}$ position using the up vector, provided in (7) and (8) (Rahmani \& Yusof, 2014; Mahrami et al., 2016;

Seyedmahmoudian et al., 2016);

$c_{p}^{k+1}=c_{p}{ }^{k}+u p(7)$

$u_{p}=C_{1}\left(G_{\text {best }}-C_{p}{ }^{k}\right)+C_{2}\left(R_{\text {best }}-c_{p}{ }^{k}\right)(8)$

The scattering of particles begins again from the updated $c_{p}$ after the $c_{p}$ is updated. The update of the $c_{p}$ by up vector is seen in Fig.

4.

\section{The ANNs+(PSO-RMO) Approach}

The main strategy here is to ensure reliable and efficient operations with highly accurate rates for wind power forecasting studies. Thus, ANNs are used for the forecasting process and the PSO-RMO model is then used to train ANNs, in this approach. In this training procedure, it was intented to optimise the nonlinear and linear components, and also, randomly occurring wide fluctuations in the data sets.

The RMO in the model has been used to construct the hybrid model thanks to its ability to focus strongly around the target point and ability to search around the target point, its low memory requirement, its rapid operation, and its ability to continue the search without missing in the local maximum with its Gbest vector (Rahmani \& Yusof, 2014; Mahrami et al., 2016; Seyedmahmoudian et al., 2016; Rahmani et al, 2015). Also, the PSO, which is also included in the model, is able to memorize the coordinates of the particles, their velocities, the best suitability amounts it has achieved so far and the coordinates it has obtained, and to take into account its own best past coordinates and the experiences of its most successful neighbor while determining its next movements (Kennedy \& Eberhart,1995; Eberhart \& Kennedy, 1995; Kennedy \& Eberhart, 1997; Kennedy et al., 2001) features were used.

The ANNs+(PSO-RMO) approach was designed to be able to obtain these two unique features from a single algorithm by taking advantage of the distinguishing singular characteristics of PSO and RMO, increasing system stability, more reliability and rapid forecasting studies (Kerem \& Saygin, 2019; Kerem et al., 2019; Kerem, 2021).

The first stage in the method is to initialization the weight parameters of the ANNs. Second, it continues with the application of problem restrictions and bounds, as well as the preservation of the best values by assessing all particle positions. After controlling the generation number, if it is even, RMO runs, otherwise, PSO runs, and the particles are scattered. After this process, the ANNs' location matrix-weight parameters are updated, and the stopping criteria are re-evaluated. If the criteria are not sufficient, the process returns to the "Evaluate all particles locations and store best values" section, and if sufficient, the process ends with bringing the best values. The model's flowchart is shown in Fig. 5.

The pseudo-code for the ANNs+(PSO-RMO) approach is shown in Fig. 6.

In the model, the data set was separated into $70 \%$ for training process, $15 \%$ for validation process and $15 \%$ for testing process using MATLAB R2017b, as shown in Fig. 7.

\section{Performance Evaluation}

The effectiveness of the novel hybrid metaheuristic approach for wind power forecasting studies is examined in this section. With the exception of wind speed data, all wind power forecasting performances carried out using temperature, humidity, and pressure data. Indeed, it is a major obstacle to prevent the success rate, and it was deliberately created. The other obstacle is the height difference between the sensors. It means the WMS-1 and the WMS-2 data for temperature $(3 \mathrm{~m})$, humidity $(3 \mathrm{~m})$, and pressure $(3.5 \mathrm{~m})$ were used to perform wind power forecasting experiments at $61 \mathrm{~m}$ and $60.3 \mathrm{~m}$, respectively. The blog diagram of the model is given in Fig. 9 .

The performance results were recorded for ANNs+(PSO-RMO) approach and the other four hybrid metaheuristics. The performance of these hybrid models has been seriously affected by making wind power predictions with no wind speed data. That is, all hybrid 
models performed wind power predictions using temperature, humidity and pressure data. Figure 10 illustrates actual and estimated wind power curves for WMS-1 for the ANNs+(PSO-RMO) approach.

According to Fig. 10 actual and estimated plots are so close, thus, error values are RMSE, NRMSE, PSNR, MSE, MAPE and R obtained $2.091,0.1673,41.72,4.732,2.068,0.9993$ respectively. Changing of fitness value of ANNs+(PSO-RMO) approach for WMS-1 is given in Fig. 11.

Figure 12 shows actual and estimated curves of wind power forecasting using ANNs+(PSO-RMO) approach for WMS-2. It belongs to the 24-hour frequency and the 15-day time record, October.

According to Fig. 12, actual and estimated curves are almost overlapping, thus, error values are RMSE, NRMSE, PSNR, MSE, MAPE and $\mathrm{R}$ are $0.5857,0.03425,52.78,0.343,1.379$ and 0.9995 respectively. Changing of fitness value of ANNs+(PSO-RMO) approach for WMS-2 is given in Fig. 13.

Error criteria includes PSNR, MSE, RMSE, MAPE is given in Table 3 . Here, $A_{i}$ represents the actual value, $F_{i}$ is the predicted value, $N$ is the number of observations and $M A X I$ represents the maximum pixel value of the picture.

Table 3 Error criteria (Varanasi \& Tripathi, 2016; Sivakumar, 2017; Guo et al., 2011; Kirbas, 2018; Zhao, 2016)

Peak Signal to Noise Ratio (PSNR)

$$
P S N R=10 \log _{10}\left(\frac{M A X_{t}^{2}}{M S E}\right)=20 \log _{10}\left(\frac{M A X_{t}}{\sqrt{M S E}}\right)
$$

Mean Squared Error (MSE)

$$
M S E=\frac{1}{N} \sum_{i=1}^{N}\left(A_{i}-F_{i}\right)^{2}
$$

Root Mean Squared Error (RMSE)

$$
R M S E=\sqrt{\frac{1}{N} \sum_{i=1}^{N}\left(A_{i}-F_{i}\right)^{2}}
$$

Mean Absolute Percentage Error (MAPE)

$$
\text { MAPE }=\frac{1}{N} \sum_{i=1}^{N}\left|\frac{A_{i}-F_{i}}{A_{i}}\right| * 100
$$

The test errors for WMS-1 and WMS-2 (50run) and the comparative results of MAPE of test error (50run) are given in Table 4 and Table 5, respectively. According to Table 4, the ANNs+(PSO-RMO) approach is the most effective with the lowest errors in all performances. 
Table 4

Test errors for WMS-1 and WMS-2 (50run)

\begin{tabular}{|c|c|c|c|c|c|c|}
\hline & & ANNs + PSO & ANNs + ACO & ANNs + RMO & ANNs + GA & ANNs+(PSO-RMO) \\
\hline \multirow{6}{*}{$\begin{array}{l}\text { WMS-1: August } \\
\text { record frequency: } \\
\text { 24-hour } \\
\text { record time: 15- } \\
\text { day }\end{array}$} & $\mathrm{R}$ & 0.999 & 0.999 & 0.996 & 0.999 & 0.999 \\
\hline & MAPE & 2.108 & 2.165 & 4.807 & 2.100 & 2.068 \\
\hline & PSNR & 41.990 & 42.797 & 34.670 & 43.031 & 41.720 \\
\hline & MSE & 4.109 & 3.414 & 22.210 & 3.235 & 4.372 \\
\hline & RMSE & 2.027 & 1.847 & 4.712 & 1.798 & 2.091 \\
\hline & NRMSE & 0.162 & 1.231 & 0.377 & 1.199 & 0.167 \\
\hline \multirow{6}{*}{$\begin{array}{l}\text { WMS-2: October } \\
\text { record frequency: } \\
\text { 24-hour } \\
\text { record time: } 15- \\
\text { day }\end{array}$} & $\mathrm{R}$ & 0.999 & 0.994 & 0.992 & 0.983 & 0.999 \\
\hline & MAPE & 1.428 & 6.796 & 6.102 & 12.391 & 1.379 \\
\hline & PSNR & 52.62 & 40.507 & 40.950 & 35.764 & 52.780 \\
\hline & MSE & 0.355 & 5.784 & 5.227 & 17.245 & 0.343 \\
\hline & RMSE & 0.596 & 2.405 & 2.286 & 4.152 & 0.585 \\
\hline & NRMSE & 0.034 & 0.320 & 0.133 & 0.553 & 0.034 \\
\hline & $\begin{array}{l}\text { reviation- } \\
\text { ial Moven }\end{array}$ & $\begin{array}{l}\text { : Ant Colony } \\
\text { Optimization }\end{array}$ & mization, GA: & netic Algorithn & O: Particle S & rm Optimization, RMO \\
\hline
\end{tabular}

Table 5 provides comparative MAPE results for test errors, including the best, average, worst and standard deviation values.

Table 5

Comparative results of MAPE of test error (50run)

\begin{tabular}{|c|c|c|c|c|c|c|}
\hline & & $\begin{array}{l}\text { ANNs + } \\
\text { PSO }\end{array}$ & $\begin{array}{l}\text { ANNs + } \\
\text { ACO }\end{array}$ & $\begin{array}{l}\text { ANNs + } \\
\text { RMO }\end{array}$ & $\begin{array}{l}\text { ANNs + } \\
\text { GA }\end{array}$ & $\begin{array}{l}\text { ANNs+(PSO- } \\
\text { RMO) }\end{array}$ \\
\hline \multirow{4}{*}{$\begin{array}{l}\text { WMS-1: August } \\
\text { record freq: } 24 \text {-hour } \\
\text { record time: } 15 \text {-day }\end{array}$} & best & 2.108 & 2.165 & 4.807 & 2.100 & 2.068 \\
\hline & average & 2.861 & 3.552 & 14.488 & 3.055 & 2.118 \\
\hline & worst & 7.450 & 6.602 & 23.440 & 5.911 & 2.871 \\
\hline & $\begin{array}{l}\text { standard } \\
\text { deviation }\end{array}$ & 0.977 & 1.154 & 5.670 & 0.946 & 0.161 \\
\hline \multirow{4}{*}{$\begin{array}{l}\text { WMS-2: October } \\
\text { record freq: } 24 \text {-hour record time: } 15 \text { - } \\
\text { days }\end{array}$} & best & 1.428 & 6.796 & 6.102 & 12.391 & 1.379 \\
\hline & average & 5.481 & 17.592 & 23.885 & 17.587 & 3.078 \\
\hline & worst & 11.150 & 31.622 & 33.990 & 29.030 & 3.113 \\
\hline & $\begin{array}{l}\text { standard } \\
\text { deviation }\end{array}$ & 2.584 & 5.831 & 9.051 & 3.618 & 0.245 \\
\hline
\end{tabular}

According to Table 5, WMS-1 (august) average MAPE (50run) values are 2.861, 3.552, 14.488, 3.055 and 2.118 for ANNs + PSO, ANNs + ACO, ANNs + RMO, ANNs + GA and ANNs+(PSO-RMO), respectively. For WMS-2 (October) average MAPE (50run) values are 5.481, 17.592, 23.885, 17.587 and 3.078 for ANNs + PSO, ANNs + ACO, ANNs + RMO, ANNs + GA and ANNs+(PSO-RMO), respectively. Thus, when Table 5 is analyzed, it has seen that the ANNs+(PSO-RMO) approach is the most efficient model of all the optimization algorithms.

The test error average MAPE values (50run) are shown in Fig. 14. Average test error values are 2.118 and 3.078 for WMS-1: August and WMS-2: October, respectively. Thus, the ANNs+(PSO-RMO) model achieved the most impressive results among the other hybrid metaheuristic models. 


\section{Conclusion}

Fossil-fueled power plants emit $\mathrm{CO}_{2}$ and other greenhouse gases into the atmosphere while generating electricity energy. These gases are harmful to the environment and ecosystem, and also threaten all living organisms. However, wind power plants, on the other hand, do not affect the environment while generating electricity; they are an environmentally friendly and clean energy source. One of the biggest obstacles for these power plants can be the difficulty of accurate wind power forecasting due to the intermittent and stochastic structure of the wind.

Wind power forecasting studies were performed in this research study using ANNs+(PSO-RMO) approach, a stronger and more powerful hybrid metaheuristic model. The model's performance was evaluated using real-time data gathered from two separate locations (WMS-1 and WMS-2). All of the performances were carefully plotted and recorded. The efficiency of the hybrid metaheuristic approach was compared to other hybrids such as ANNs + PSO, ANNs + ACO, ANNs + RMO, and ANNs + GA.

According to the error values, the newer hybrid metaheuristic approach has the smallest test errors among the existing hybrid models (see Table 4). Also, it was found that the ANNs+(PSO-RMO) approach provided a strongly accurate and consistent performance for wind power forecasting studies, even at abrupt fluctuations. Thus, with the smallest error rate, system reliability, and compact structure, a novel hybrid metaheuristic approach for wind power forecasting studies has contributed to the literature.

\section{Declarations}

\section{Acknowledgement:}

Digest version of this paper was presented on International Symposium of ISEF2019, Nancy, France (IEEE). The authors thank to West Mediterranean Development Agency (BAKA) and MAKÜ Scientific Research Projects Commission for funding to WMS-1. And also, the authors thank to Demirciler Wind Energy Plant (Vestel Zorlu Group) for collaboration on providing WMS-2 data.

Authors' contribution AK: idea, data gathering, writing-original draft preparation, methodology, software. AS: investigation, draft reviewing, editing, supervision. RR: methodology, software, draft reviewing, editing. All the authors read and approved the final manuscript.

Funding This work was funded by West Mediterranean Development Agency (for WMS-1 with TR61/ 13/ DFD/ 036 project number) and MAKÜ Scientific Research Projects Commission (for WMS-1 with 0212 - Gudumlu -13 with project number).

Availability of data and materials Not applicable

Ethics approval and consent to participate Not applicable.

Consent for publication Not applicable.

Competing interests The authors declare no competing interests.

Financial interests The authors declare they have no financial interests

\section{References}

1. Azimi R, Ghofrani M, Ghayekhloo M (2016) A hybrid wind power forecasting model based on data mining and wavelets analysis. Energy Convers Manag 127:208-225

2. Catalao JPS, Pousinho HMI, Mendes VMF (2011) Hybrid wavelet-PSO-ANFIS approach for short-term wind power forecasting in Portugal. IEEE Trans Sustain Energy 2(1):50-59

3. Catalao JPS, Pousinho HMI, MendesVMF (2011) Hybrid intelligent approach for short-term wind power forecasting in Portugal. The Institution of Engineering Technology Renewable Power Generation 5(3):251-257

4. Chitsaz H, Amjady N, Zareipour H (2015) Wind power forecast using wavelet neural network trained by improved clonal selection algorithm. Energy conversion Management 89:588-598

Page $9 / 19$ 
5. Çetin NS (2006) Şebeke bağlantısız PM generatörlü rüzgar türbinlerinin YSA ile sistem optimizasyonu. Doktora Tezi, Ege Üniversitesi Fen Bilimleri Enstitüsü, İzmir

6. Guo ZH, Wu J, Lu HY, Wang JZ (2011) A case study on a hybrid wind speed forecasting method using BP neural network. KnowlBased Syst 24(7):1048-1056

7. Debbağ Y, Yilmaz EN (2015) Internet based monitoring and control of a wind turbine via PLC. 3rd International Istanbul in Smart Grid Congress and Fair (ICSG) 1-5, IEEE April, 2015

8. Eberhart R, Kennedy J (1995) A new optimizer using particle swarm theory. Micro Machine and Human Science Proceedings of the Sixth International Symposium, Nagoya, Japan

9. Golding EW (1955) The generation of electricity by wind power. New York: Philosophical Library, 318

10. Gourieres DL (1982) Wind power plants. Oxford: Pergamon Press, 1-100

11. Haque AU, Nehrir MH, Mandal P (2014) A hybrid intelligent model for deterministic and quantile regression approach for probabilistic wind power forecasting. The Institute of Electrical Electronics Engineers Transactions on Power Systems 29(4):1663-1672

12. Kassa Y, Zhang JH, Zheng DH, Wei D (2016) A GA-BP hybrid algorithm based ANN model for wind power prediction. 4th IEEE International Conference on Smart Energy Grid Engineering, 158-163, Oshawa, Canada

13. Kennedy J, Eberhart RC (1995) Particle swarm optimization. Neural Networks, Proceedings, IEEE International Conference on, Perth, WA, Australia, 4: 1942-1948

14. Kennedy J, Eberhart RC (1997) A discrete binary version of the particle swarm algorithm. Proc of the Conference on Systems, Man, and Cybernetics, Orlando, FL, United States

15. Kennedy J, Eberhart RC, Shi Y (2001) Swarm intelligence. Morgan Kaufmann Publishers, San Francisco, p 512

16. Kerem A, Atayeter Y, Görgülü S, Salman S (2014) Mehmet Akif Ersoy Üniversitesi İstiklal Yerleşkesi'nin rüzgar enerji fizibilite alt yapisinin hazirlanmasi ve uygulanmasi. Mehmet Akif Ersoy Üniversitesi Fen Bilimleri Enstitüsü Dergisi 5(1):18-24

17. Kerem A, Saygin A (2019) Scenario-based wind speed estimation using a new hybrid metaheuristic model: particle swarm optimization and radial movement optimization. Measurement Control 52(5-6):493-508

18. Kerem A, Saygin A, Rahmani R (2019) Wind power forecasting using a new and robust hybrid metaheuristic approach: a case study of multiple locations, 19th International Symposium on Electromagnetic Fields in Mechatronics, Electrical and Electronic Eng. (ISEF), Nancy, France

19. Kerem A (2021) Design, implementation and speed estimation of three-phase $2 \mathrm{~kW}$ out-runner permanent magnet BLDC motor for ultralight electric vehicles. Electrical Engineering, Springer

20. https://doi.org/10.1007/s00202-021-01279-5

21. Kirbas I (2018) İstatistiksel metotlar ve yapay sinir ağları kullanarak kısa dönem çok adımlı rüzgâr hızı tahmini. Sakarya Üniversitesi Fen Bil Enst Der 22(1):24-38

22. Kusiak A, Zheng H, Song Z (2009) Wind farm power prediction: a data-mining approach. Wind Energy 12(3):275-293

23. Liang Z, Liang J, Zhang L, Wang C, Yun Z, Zhang X (2015) Analysis of multi-scale chaotic characteristics of wind power based on Hilbert-Huang transform and Hurst analysis. Appl Energy 159:51-61

24. Liu Y, Zhang H, Yan J, Han S (2015) Hybrid relevance vector machine model for wind power forecasting. International Conference on Renewable Power Generation (RPG 2015), Beijing, China

25. Lund $H$ (2005) Large-scale integration of wind power into different energy systems. Energy 30(13):2402-2412

26. Mahrami M, Rahmani R, Seyedmahmoudian M, Mashayekhi R, Karimi H, Hosseini E (2016) A hybrid metaheuritic technique developed for hourly load forecasting. 2016 Wiley Periodicals Inc Complexity 21(S1):521-532

27. Osório GJ, Matias JCO, Pousinho HMI, Catalão JPS (2012) Hybrid neuro-fuzzy evolutionary approach for short-term wind power forecasting. Electrotechnical Conference (MELECON), 16th IEEE Mediterranean, Yasmine Hammamet, Tunisia

28. Osório GJ, Matias JCO, Catalão JPS (2015) Short-term wind power forecasting using adaptive neuro-fuzzy inference system combined with evolutionary particle swarm optimization, wavelet transform and mutual information. Renewable Energy 75:301307

29. Patel MR (1942) Wind and solar power systems, 380. CRC Press, New York

Page $10 / 19$ 
30. Pousinho HMI, Catalão JPS, Mendes VMF (2010) Wind power short-term prediction by a hybrid PSO-ANFIS approach. MELECON, 15th IEEE Mediterranean Electrotechnical Conference, Valletta, Malta

31. Ragheb M, Ragheb AM (2011) Wind turbines theory - the betz equation and optimal rotor tip speed ratio. Fund. and Advanced Topics in Wind Power, Chap. 2

32. Rahmani R, Khairuddin A, Cherati SM, Pesaran HM (2010) A novel method for optimal placing wind turbines in a wind farm using particle swarm optimization (PSO). IPEC, 2010 Conference Proceedings, Singapore

33. Rahmani R, Yusof R, Seyedmahmoudian M, Mekhilef S (2013) Hybrid technique of ant colony and particle swarm optimization for short term wind energy forecasting. J Wind Eng Ind Aerodyn 123:163-170

34. Rahmani R, Yusof R (2014) A new simple, fast and efficient algorithm for global optimization over continuous search-space problems: radial movement optimization. App. Maths. and Comp. 287-300

35. Rahmani R, Rubiyah Y, Ismail N (2015) A new metaheuristic algorithm for global optimization over continuous search space. International Conference on Intelligent Computing 9: 1335-1340

36. Riahy G, Abedi M (2008) Short term wind speed forecasting for wind turbine applications using linear prediction method. Renewable Energy 33(1):35-40

37. Seyedmahmoudian M, Horan B, Rahmani R, Than A, Stojcevski A (2016) Efficient photovoltaic system maximum power point tracking using a new technique. Energies 9:147

38. Sharifian A, Ghadi MJ, Ghavidel S, Li L, Zhang J (2018) A new method based on Type-2 fuzzy neural network for accurate wind power forecasting under uncertain data. Renewable Energy 120:220-230

39. Sivakumar R (2017) Denoising of computer tomography images using curvelet transform. ARPN Journal of Engineering Applied Sciences 2(1):21-26

40. Varanasi J, Tripathi MM (2016) A comparative study of wind power forecasting techniques-a review article. Computing for Sustainable Global Development (INDIACom)3rd International Conference, New Delhi, India

41. Xiaochen W, Peng G, Xiaobin H (2011) A review of wind power forecasting models. Energy Procedia 2:770-778

42. Yang M, Yun-peng J, Qian W, Chen L (2013) A combination method research for wind power predication based on dynamic weight. Journal of Northeast Dianli University 33(1/2):131-136

43. Yang M, Shaoshuai W (2016) A review of wind power \& forecasting prediction. Probabilistic Methods Applied to Power Systems (PMAPS), Int. Conference on, Beijing, China. 16-20 Oct

44. Zhang W, Liu F, Zheng X, Li Y (2015) A hybrid EMD-SVM based short-term wind power forecasting model. Power and Energy Engineering Conference (APPEEC), Brisbane, Australia

45. Zhao W, Wei YM, Su Z (2016) One day ahead wind speed forecasting: a resampling-based approach. Appl Energy 78:886-901

\section{Figures}




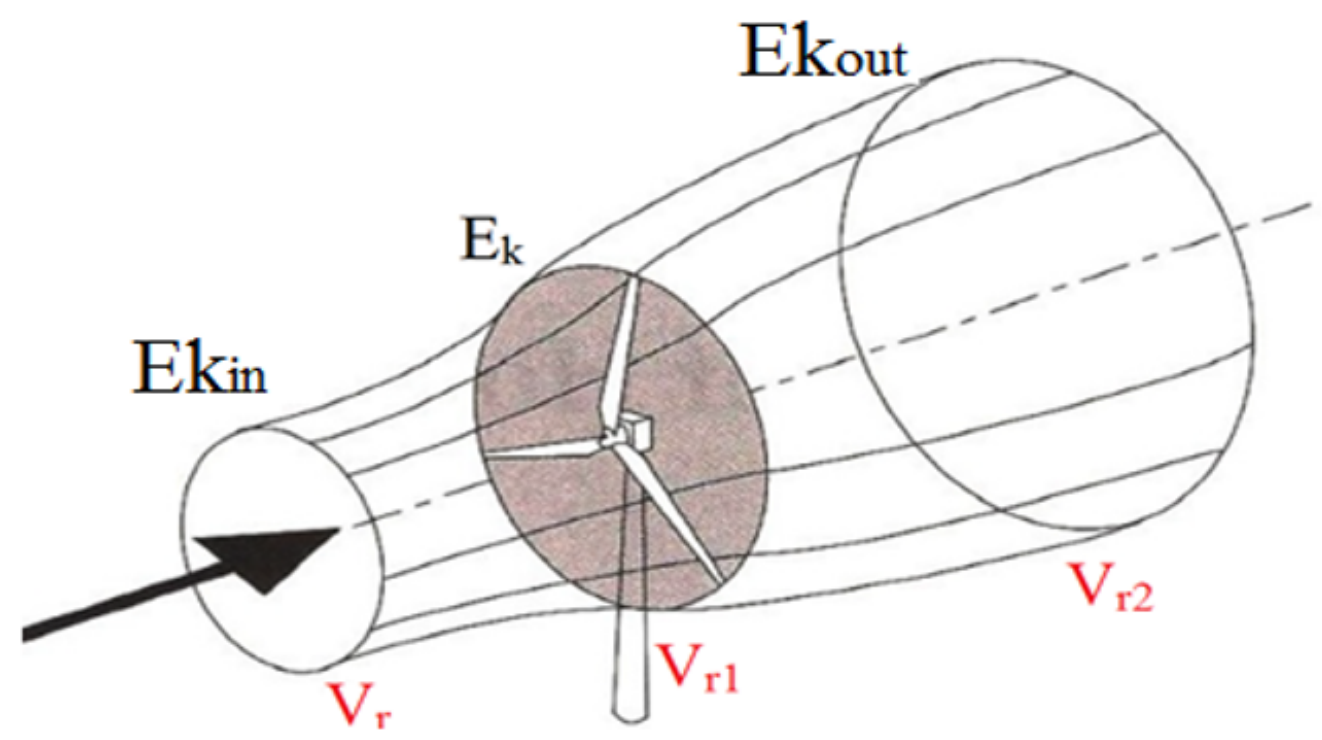

\section{Figure 1}

Kinetic energy flow of wind around a wind turbine (Rahmani et al., 2010)

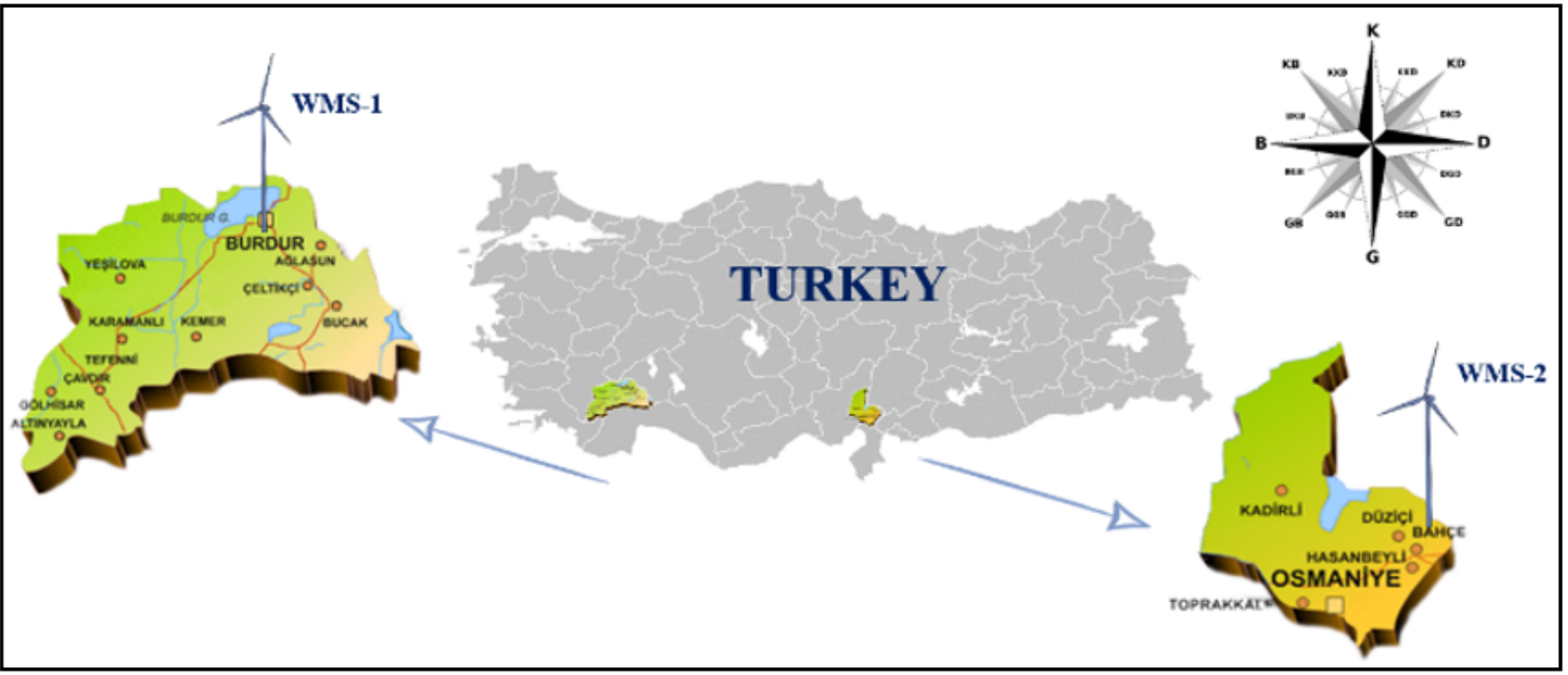

Figure 2

Locations of WMS-1 and WMS-2 


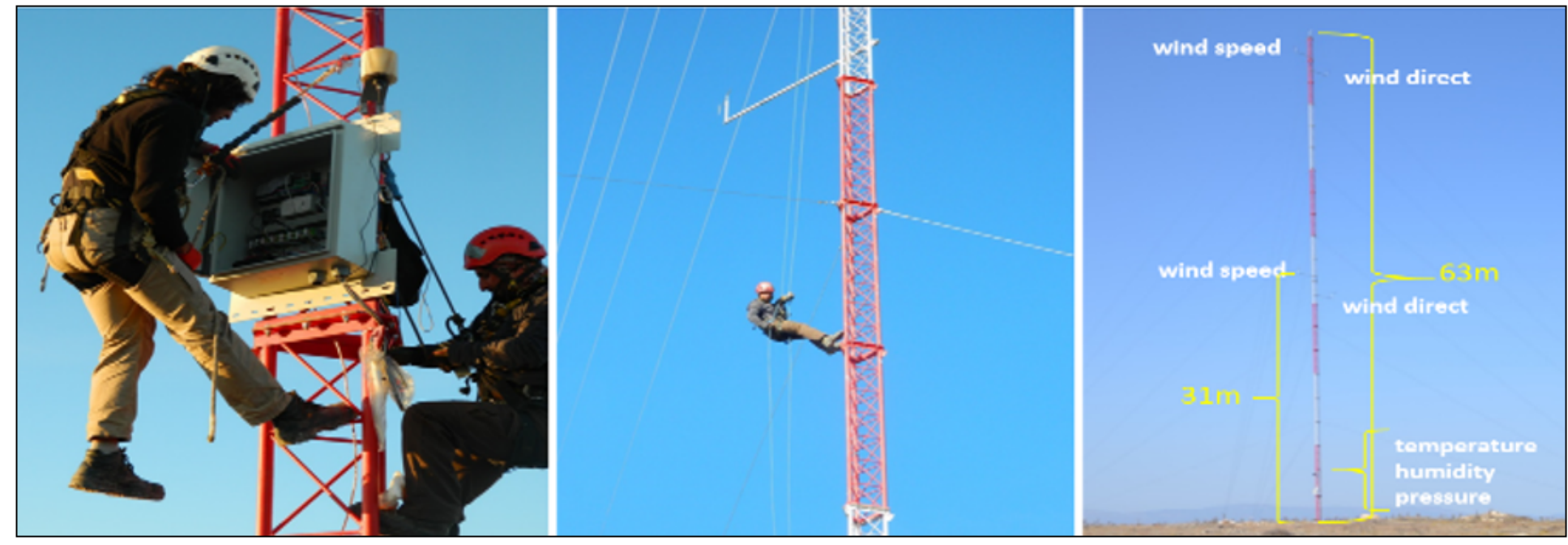

Figure 3

Installation works of WMS-1 and sensors

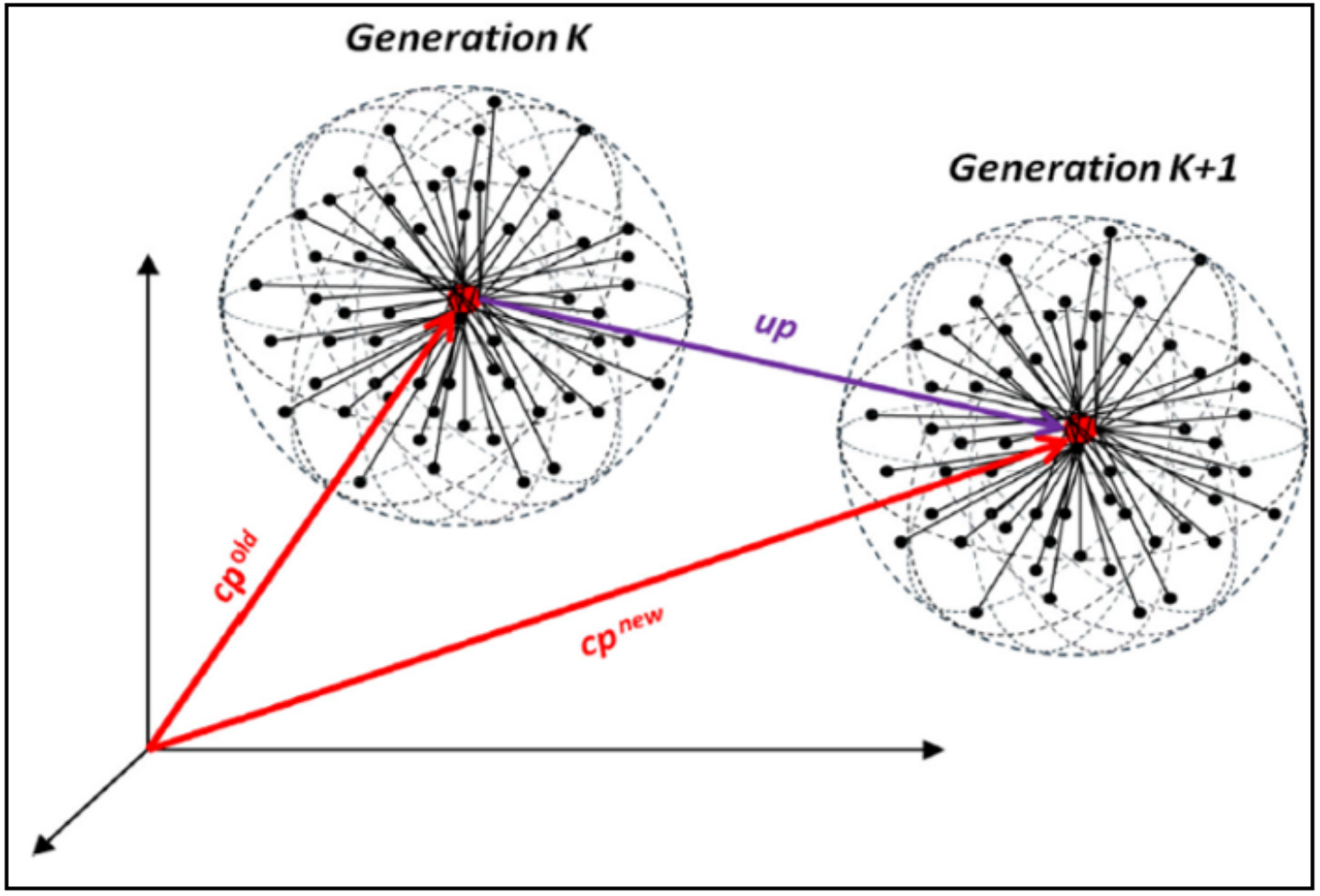

Figure 4

Updating the cp by up vector (Rahmani \& Yusof, 2014). 


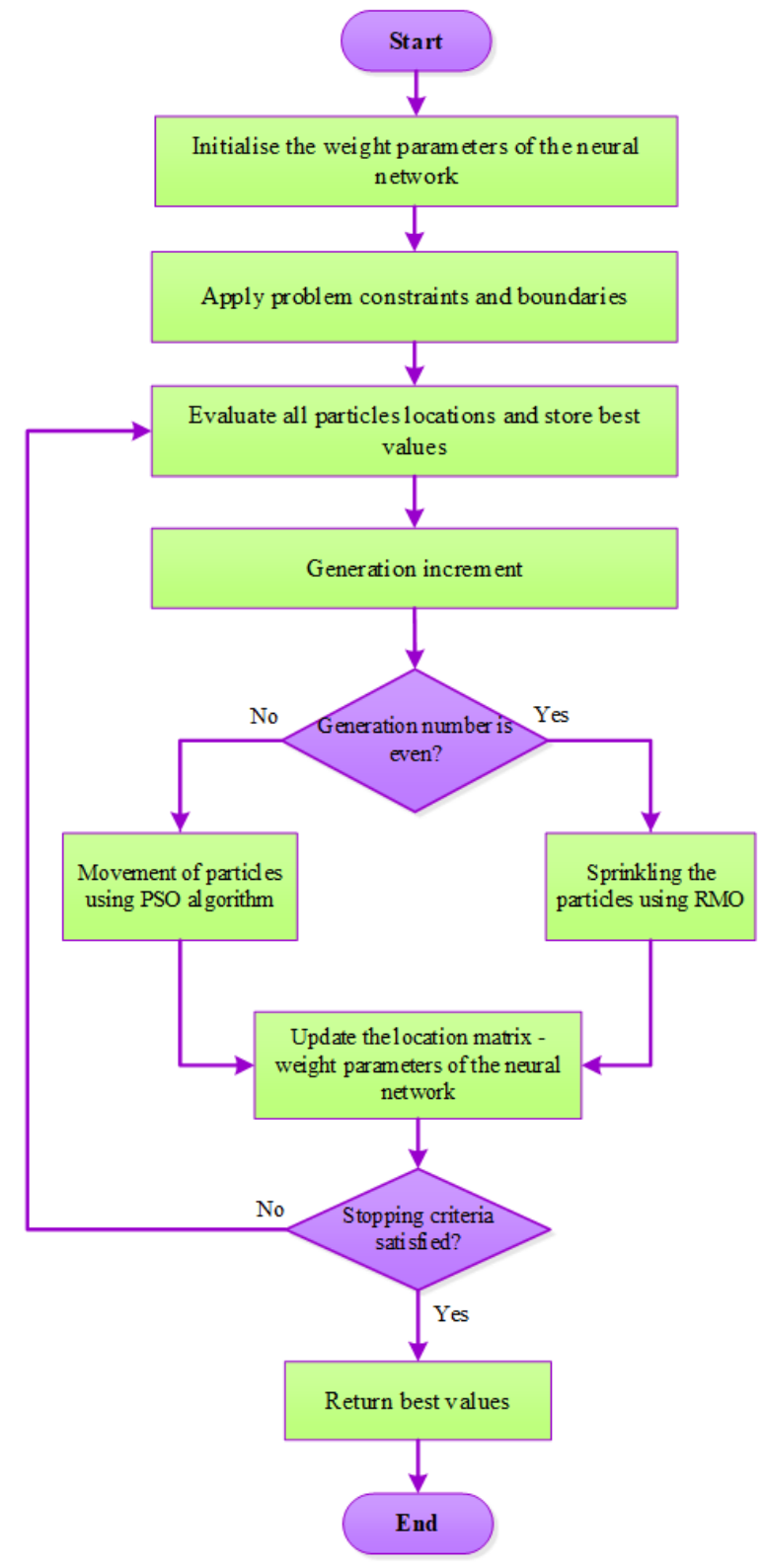

Figure 5

Flowchart of the ANNs optimization procedure 
Develop solution space by setting parameter space used in the algorithms Set parameters of RMO $\mathrm{W}, \mathrm{Cl}, \mathrm{C2}, \mathrm{C} 3$

FOR every sample in population

FOR every dimension in a sample

$X 0<$ - Initialize corresponding sample dimension as the difference of upper boundary and lower boundary END FOR multiplied with a random number in space 0 and $l$

END FOR

Set initial population as $X 0$

Set velocity vector as 0.7 times $X 0$

FOR every sample in population

END FOR

FO $<$ - Evaluate initialized samples

Store minimum value and index of Initialized samples $F O$

Set $P B E S T$ as $X 0$ and GBEST as the minimum valued sample of $X 0$ obtained from $F O$ in the previous step

Initialize RMO with parameters and store $X i$ and $C E N T R E$ values

FOR every sample in population

END FOR

$F 1<$ - Evaluate samples obtained as $X i$

Store minimum value and index of evaluated samples $F 1$

Set best index as RBESTLOC of minimum value and best sample as RBEST

obtained from the minimum value of $F 1$ through $X i$

Set GBESTLOC as RBESTLOC and GBEST as RBEST

Set Iteration count and tolerance to $I$

WHILE Iteration count and tolerance criterias are not met

IF Iteration count is even

Run RMO algortithm with calculated parameters

FOR every sample in population

Evaluate sample and store in fitness matrix

Find the best sample through this matrix and update $G B E S T$ iteration vector and GBESTLOC vector

END FOR

ELSE iteration count is odd

Repeat same procedure for PSO algorithm in the above

IF-END IF code clock

END IF

Show best generation of the iteration

Update iteration count by adding one

END WHILE

\section{Figure 6}

The pseudo-code of the ANNs+(PSO-RMO) approach 


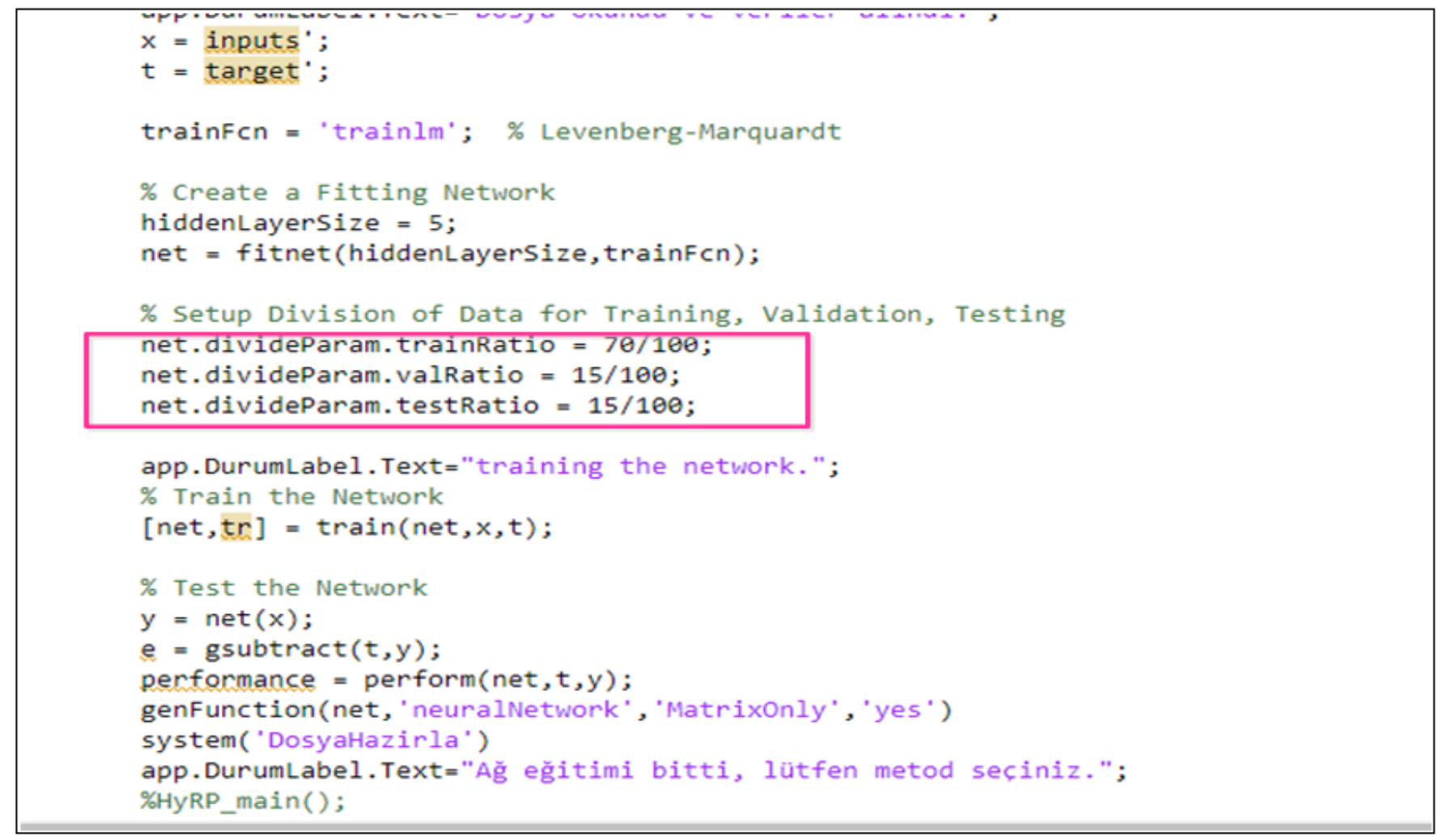

\section{Figure 7}

The data set is split into three parts (70 \% training, $15 \%$ validation, $15 \%$ testing)

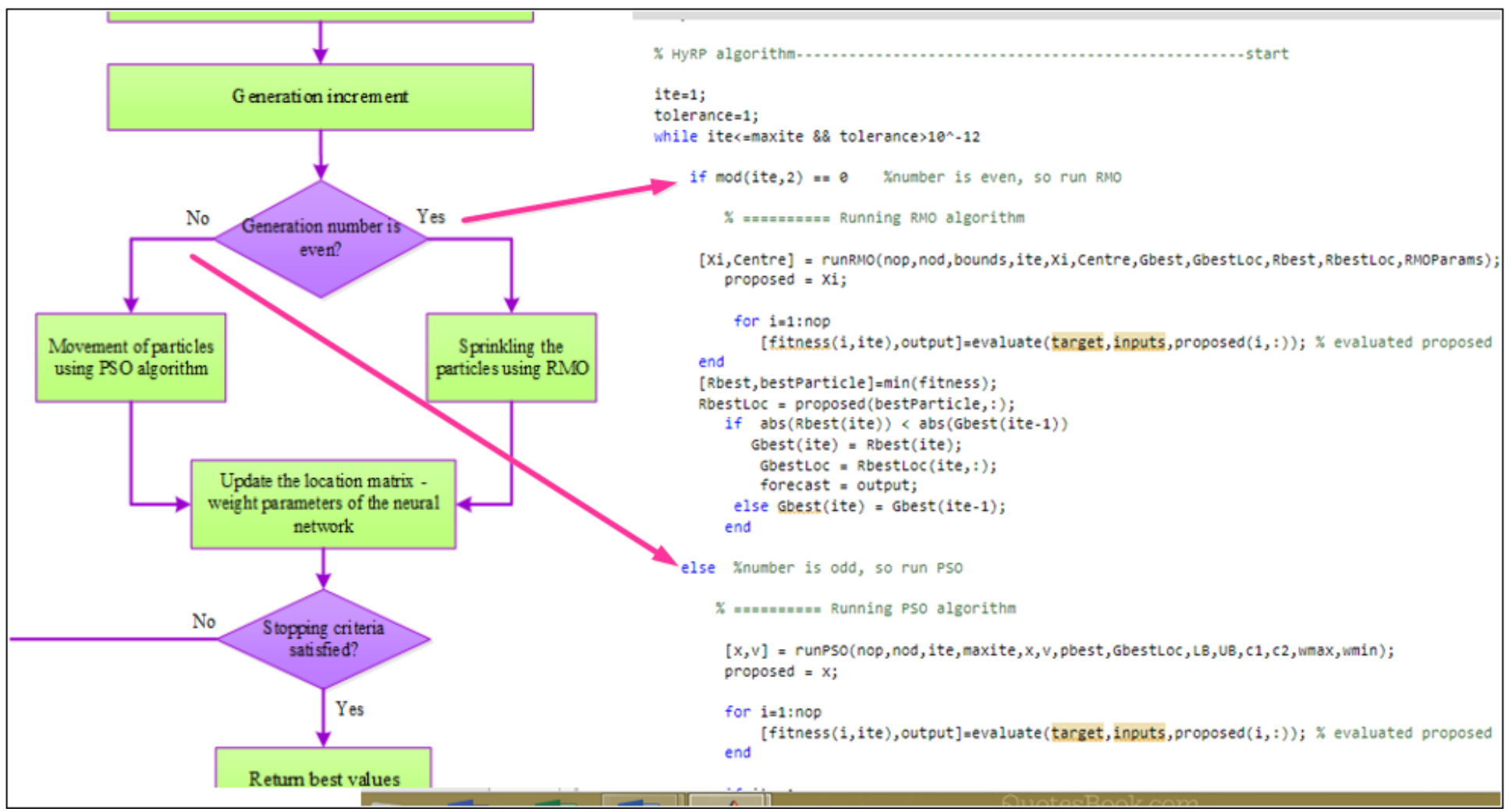

Figure 8

Controlling the number of generations and forwarding the algorithm to RMO or PSO 


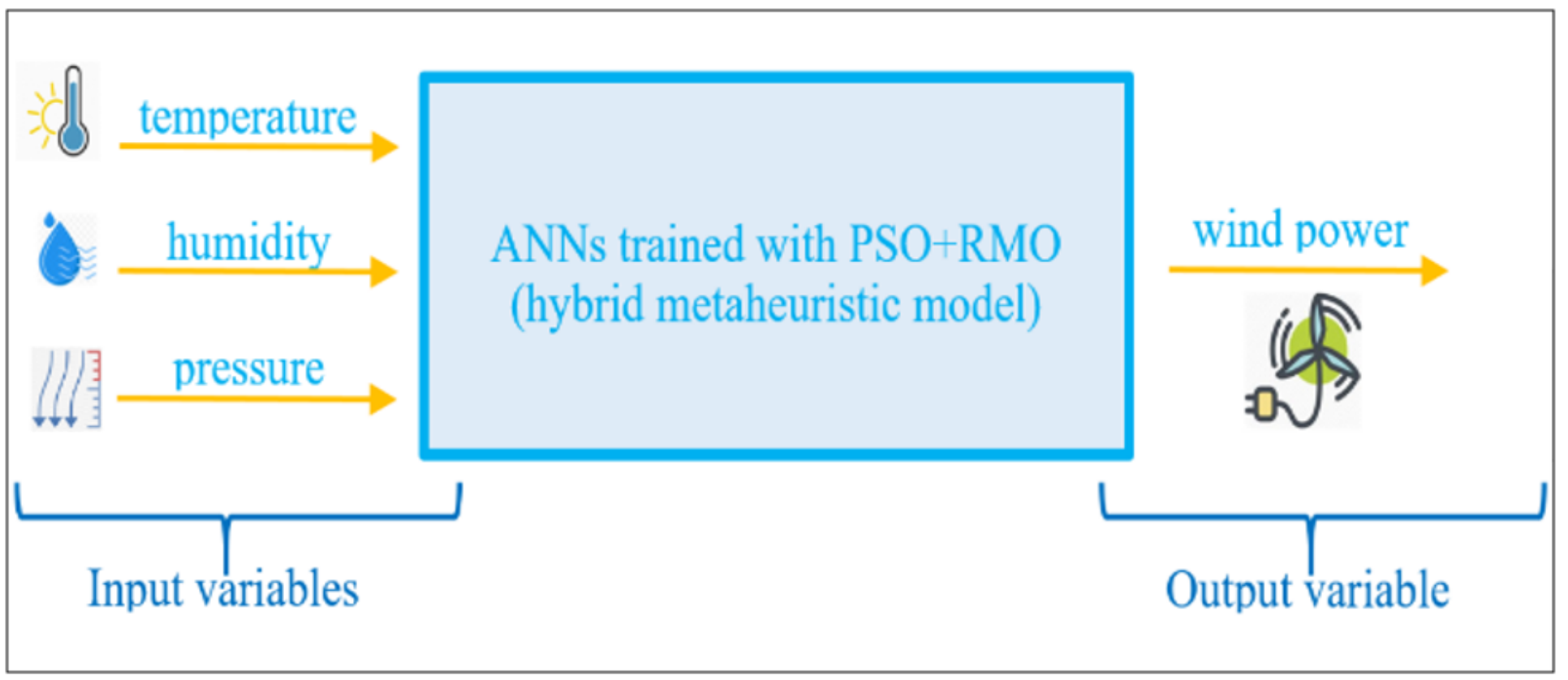

Figure 9

The blog diagram of the model

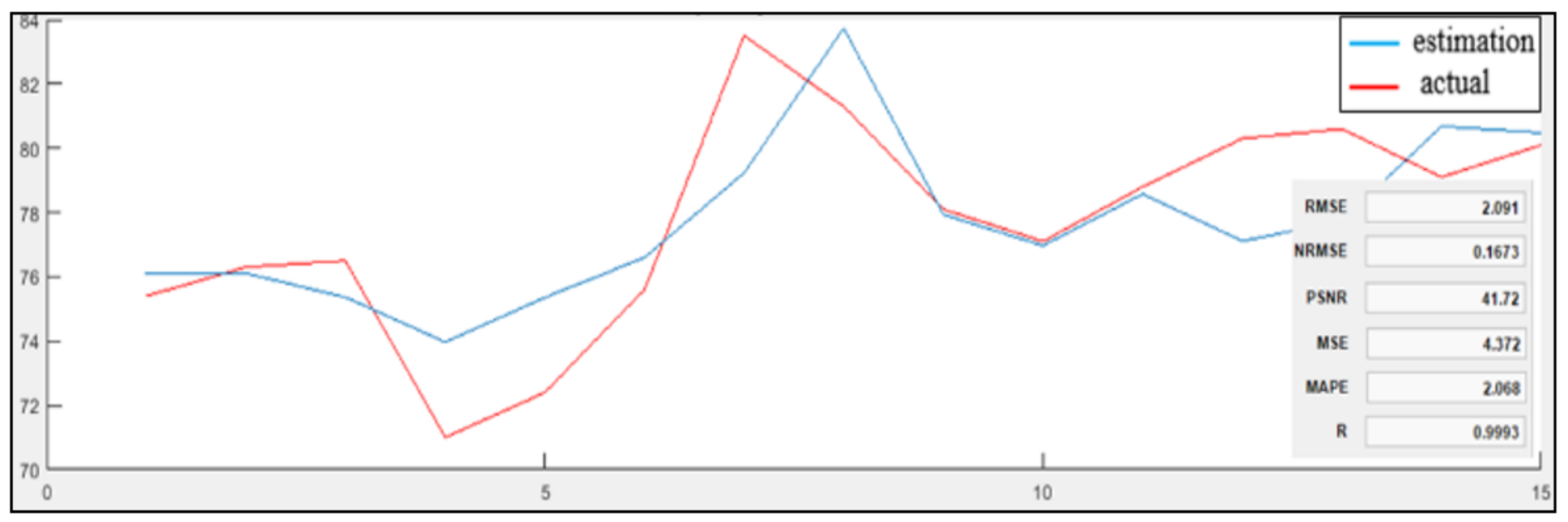

Figure 10

Wind power forecasting curves, both actual and estimated using ANNs+(PSO-RMO) approach (WMS-1: record frequency: 24-hour, record time: 15-day, August) 


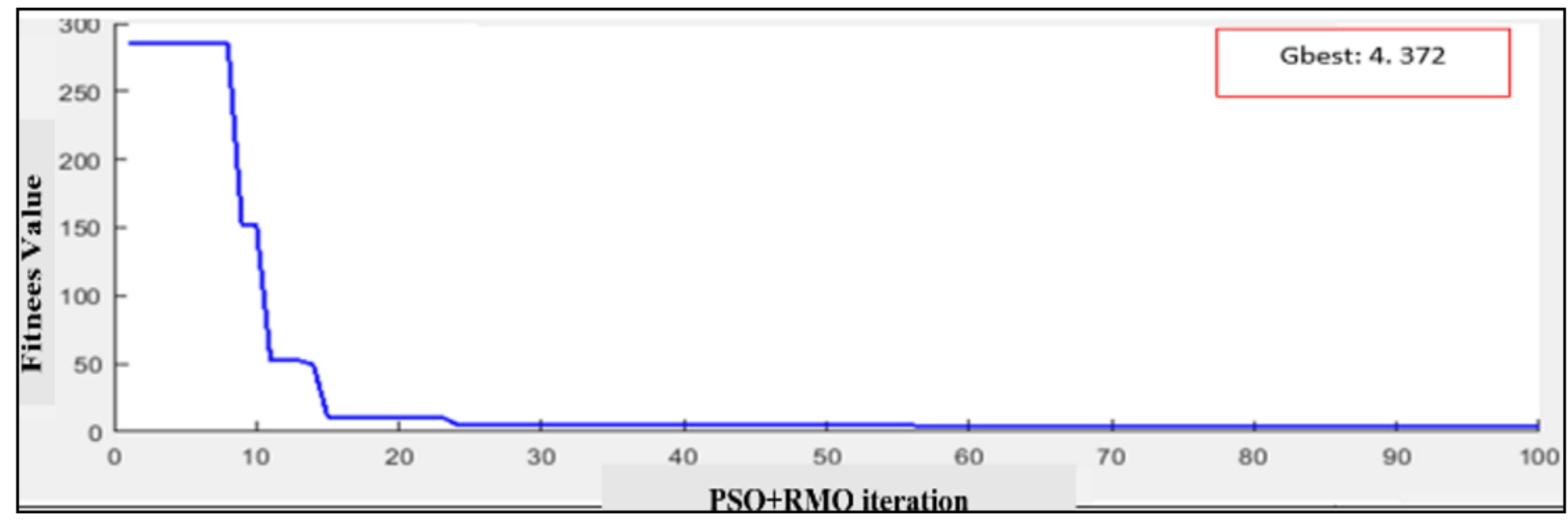

\section{Figure 11}

Changing of fitness value of ANNs+(PSO-RMO) approach (WMS-1: record frequency: 24-hour, record time: 15-day, August)

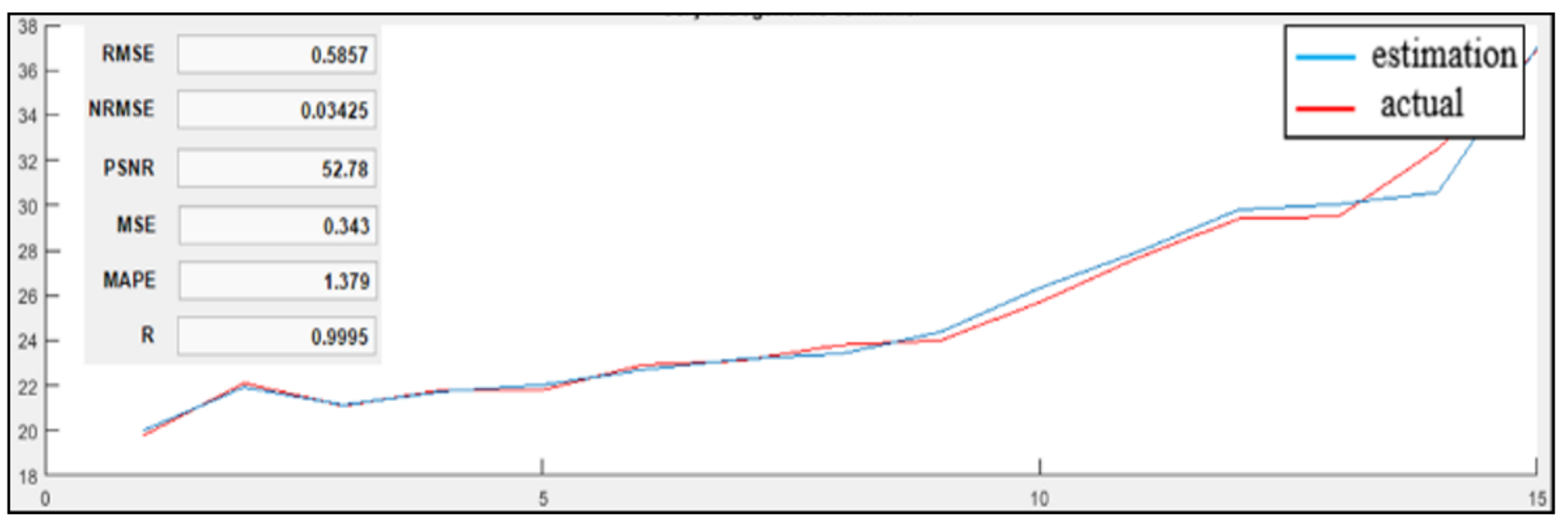

Figure 12

Wind power forecasting curves, both actual and estimated using ANNs+(PSO-RMO) approach (WMS-2: record frequency: 24-hour, record time: 15-day, October)

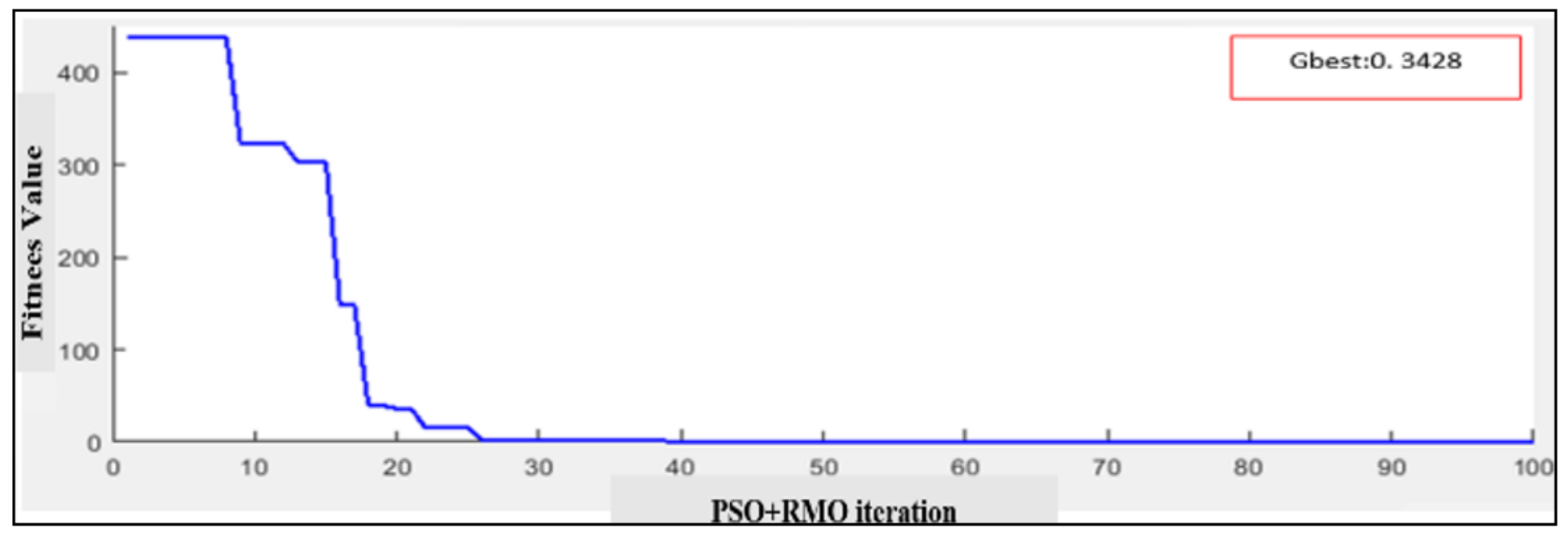

Figure 13 
Changing of fitness value of ANNs+(PSO-RMO) approach (WMS-2, record frequency: 24-hour, record time: 15-day, October)

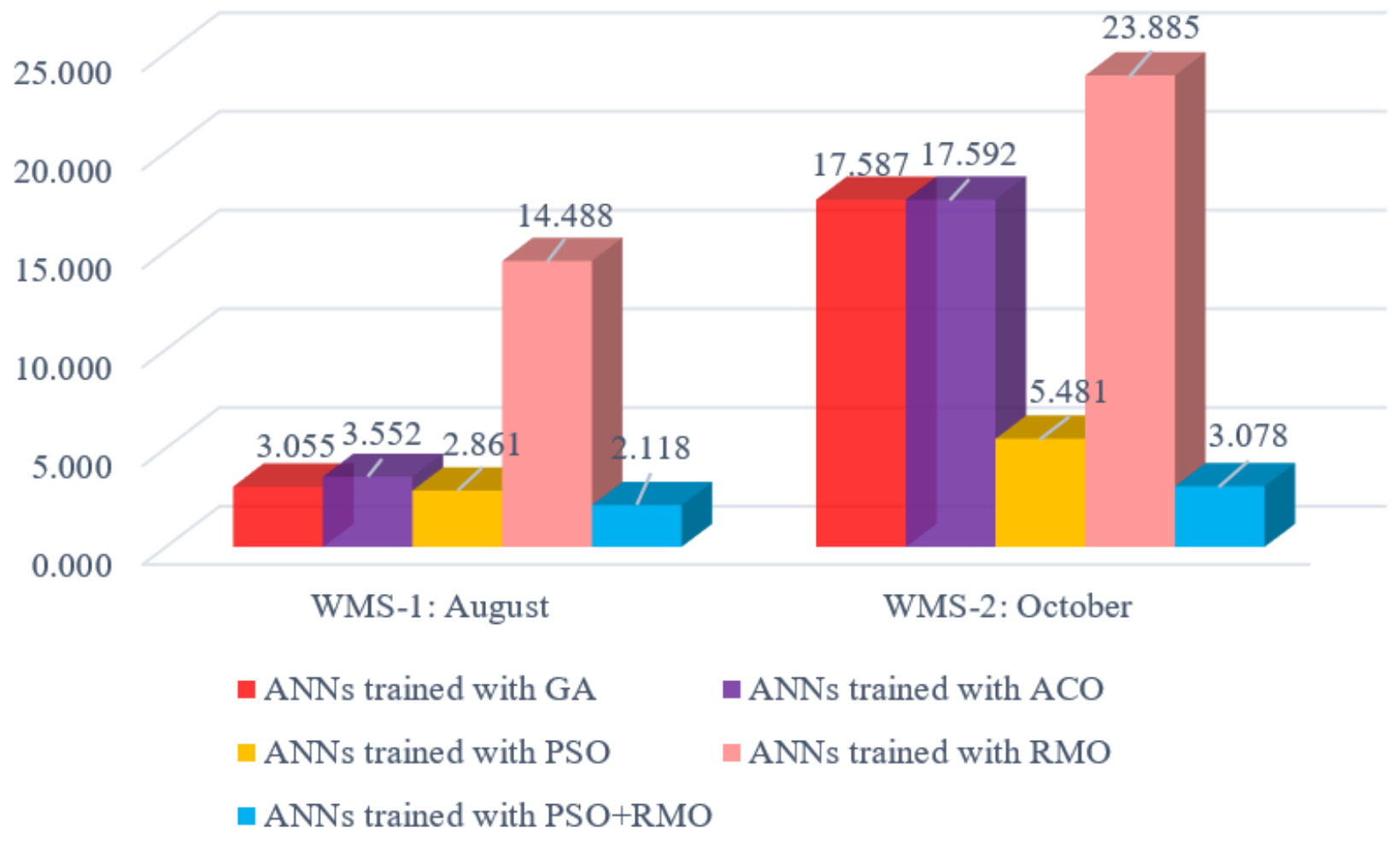

Figure 14

Average MAPE values of test error for wind power forecasting (50run) 